\title{
Study on Religious Musical Cultural Identity of Dai People and Thailand Xishuangbanna in Yunan Province from Cross-cultural Perspective
}

\author{
Haiyan Wang \\ Kunming University, Kunming, China
}

Keywords: cross culture; Dai nationality; Thailand; religious music; cultural identity

\begin{abstract}
Due to the geographical proximity and similar climatic conditions, the official and unofficial exchanges in the Dai people are frequent between Xishuangbanna and Thailand. The two nationalities belong to different countries in politics, but they have deep relations in history, culture, traditions and customs. Their culture origin have many similarities in the religious music. Cross-cultural cultural identity accelerates the integration of music. It has made lasting peace and development the theme of the times between China and Thailand. At present, there are many shortcomings in cross-cultural research especially in the research field of national music culture with neighboring countries. Therefore, the research on music culture of Dai and Thailand ethnic religion can effectively complement and improve the research of music culture in China based on cross-cultural perspective.
\end{abstract}

\section{Cultural Identity}

The theory of "cultural identity" came into being in the early 1950s. It was put forward by American scholar Ericson. It began to be used for psychological analysis, and it was widely applied to various disciplines. The essence of cultural identity is the search and determination of the sense of belonging. Similar geographical background, climate environment and way of existence are prerequisites for cultural identity. Cultural identity is an ongoing process in cross-cultural communication. Cultural identity is a core value idea formed in a common region[1]. It is an important common psychological foundation and spiritual link in the nation. Religious belief is one of the most important areas of cross-cultural identification. The dai nationality of xishuangbanna, because of its special geographical location, often belongs to the same administrative divisions as some parts of southeast Asia. The proximity of blood makes these transboundary peoples maintain a common artistic style and religious belief.

\section{The Role of Musical Cultural Identity in Intercultural Communication}

The Intercultural ethnic religion music communication based on cultural identity is the possibility of mutual integration and development. From a macro perspective, cultural identity has national identity and national identity. From the development degree of human social globalization and the current situation, researchers attach more importance to the study of national identity[2]. Therefore, we can study xishuangbanna's dai and Thai religions music by virtue of the geographical advantage of the southwest and the long history of humanistic history.

\subsection{Musical cultural identity deepens cultural exchanges among different ethnic groups.}

In cross-cultural communication, the "music borderless" of transnational national music communication concept contains the importance of music cultural identity in the process of different ethnic interactions. Music can be used as a substitute for language to express the inner world. Meanwhile, different tones, timbre, music equipment can express different emotions. Therefore, the cultural identity on music can deepen cross-cultural communication in mind. There is a long history of music communication between Dai and Dai nationality in Xishuangbanna[3]. Both of them belong to the branch of indo-buddhist Buddhism. The upper part of the south chuan Buddhism was introduced to China through Southeast Asian countries during the sui and tang 
dynasties. Dai's upper part of Buddhism was introduced directly from Lana Thai, Thailand[4]. The New Tai Lue alphabet of xishuangbanna has evolved from the northern Thai language of Lana Thai. The dai music of xishuangbanna in yunnan province and music of Buddhism in northern Thailand have similarities in classical texts, buddhist rites, percussion instruments, tunic tunes and dance music.

In fact, the Dai and Thai people in the border area belong to different countries in the political boundaries, but for a long time between the turnover has largely driven the cultural exchanges between the two peoples, but the flow of people between the two countries has greatly driven the cultural exchanges between the two peoples for a long time. In addition, the Chinese people have a more tolerant attitude towards foreign art and culture since ancient times, which is an important reason why border national cultural ecology tends to diversify.

\subsection{Musical cultural identity helps to enrich the national music culture of both sides of communication.}

From the perspective of cultural communication, the fundamental reason for the integration and development of music is the role of cultural identity psychology. Music cultural identity is an important part of cultural identity system.

The music cultural identity psychology can quickly reduce the distance between the two nations psychology and speed up the communication between different people. They will absorb each other's music culture and promote the prosperity and development of music. In the court music of ancient Thailand, it was influenced by the music of the Dai nationality, such as the chanting music temperament and the soft melody that appeared in the specific music style. Li Weilin thinks that the Dai nationality of Xishuangbanna in northern Thailand and Xishuangbanna in Yunnan province belong to the sub-culture circle of the Dai nationality. For example, the Dai ethnic groups in China and Thailand have the same rap music form - KhapLue[5]. In addition, there are many similarities between the Dai nationality of Xishuangbanna and Thailand. According to the eight tones of classification of the Dai and Thai nation, the traditional instrument, the two-stringed instrument, has a lot in common. The most representative instruments are the dai, the "ding" of the dai nationality, Thailand's "both wanghu" and "wuhu"[6]. They belongs to the string instrument. These similar cultural backgrounds constitute a highly inclusive cultural identity that has led to a myriad of relationships among the music culture between the peoples of China and Thailand. This continues to enrich the two countries' music culture.

\section{Dai and Thai religious Music Cultural Identity}

Numerous studies have shown that the higher the similarity between the habits of life and the culture and customs of the ethnic groups, the greater the ability to adapt to each other in the process of national communication. In particular, it is easier to form an ideological communication bridge in the common sense of religious belief.

\subsection{The similarity of objective geographical environment.}

The nearest distance between Yunnan and Thailand is about more than 200 kilometers. Because the distance is very close, the Dai people in Xishuangbanna and Thailand can communicate with each other frequently. China has been closely related to neighboring countries such as Thailand since ancient times, and the most important traffic thoroughfare is the development of "Ancient Tea Route"[7]. The transportation between China and East Asia and Southeast Asian countries is dominated by waterways. As China is in the upper reaches of the river, the Chinese civilization can easily be transmitted to other countries around the river, especially some the Southeast Asian countries. It is closely related to the geographical advantages of Dai nationality close to Thailand.

In addition, Dai and Thai people in similar geographical environment, they have a similar tropical climate. Many folk musical instruments are made of local materials. Coconut, ivory and other materials of musical instruments is the most common form in the Dai and Thai traditional instruments. The similarity of objective material determines the cultural identity of the subjective 
creation of music. [8]

\subsection{The advance of political power.}

The external driving force of political power is also an important factor in the formation of cross national cultural identity.In history, Thailand has no border with China, but there are official and unofficial cultural contacts between China and Thailand. The ancient traffic arteries represented by "Ancient Tea Route" played a significant role in promoting the exchange of folk culture between ancient China and Thailand. Zheng He went to the West as a large-scale cultural exchange between China and Thailand. During the reign of Ayutthaya Dynasty, the Dai people in the border areas of our country began to move to Thailand. Chinese music also spread to Thailand, which expanded the influence of the Dai music culture in the religious culture of Thailand[9]. Since the establishment of diplomatic relations between China and Thailand, the volume of trade between the two countries increased from 25 million in the early days of diplomatic relations to $\$ 76.9$ billion in 2016. China is Thailand's largest trading partner, export market and largest source of tourists. In recent years, the implementation of the "visa free" policy aimed at Thailand. This reinforces the link between China and Thailand's tourism economy. As an important part of the tourism economy, cultural communication, with the introduction of various preferential policies, such as B\&R strategy, will lead to a gradual increase in religious music with the Dai and Thailand religions near the Thailand border.

\subsection{Common Buddhist beliefs.}

The greatest cultural identity between the Dai people in Xishuangbanna and the religious culture in Thailand is that they share the same Buddhist faith. Dai culture is heavily influenced by Theravada buddhism. From the history of the Tusi, the national law, politics, culture to the folk customs, language, literature, architecture, dance are influenced by Theravada Buddhism. Dai culture are composed of religious culture and national culture. The Dai nationality and the Thai nationality in Thailand belong to the same group of Dai nationality. Although a wide range, a large number of population, the branch has more complex complicated and The cultural background and cultural connotations are complex, There are great similarities and similarities in ethnic culture and religious belief. This will form a continuous and complete range of Dai Theravada Buddhism culture circle[10].

China's Yunnan Xishuangbanna Dai area belongs to the Theravada Buddhism region. It belongs to the Buddhist branch of Buddhism with the Buddhism of Thailand. They have many similarities in the writing style and chanting scriptures. Buddhist doctrines are mostly propagated through a musical form of recitation. Theravada Buddhism also pays more attention to the "localization", especially the use of narrative poems chanting to achieve a civilizing effect[11]. This is also one of the reasons why the Dai Buddhism culture often sees the shadow of Thailand Buddhism. In the chanting style, Xishuangbanna Dai belongs to the Theravada Buddhist Chanting style. This style of chanting has two main styles, including Bairun and Baiduo. The style of Bairun is directly through the Thailand Chiang Mai, Burma Jingdong spread to Xishuangbanna China. The great power of religious belief will affect the daily life of the Dai people, especially the music creation related to people's inner feelings, which will become an important aspect of revealing their religious aspirations. Theravada Buddhism chanting music style will directly affect the Xishuangbanna Dai music style.

Because of the same Buddhist faith between the Thai and Thai nationalities, there are many similar Buddhist festivals, such as the opening section and the closing section correspond to the beginning of the summer meditation and the beginning of the summer meditation retreat .Since modern times, with the increase of the number of Chinese in Thailand, Mahayana Buddhism has developed rapidly in Thailand. Many Mahayana Buddhism associations and monasteries have been built up. This has promoted the blending and development of Buddhist music culture in China and Thailand. 


\section{Discussion}

Musical communication and cultural identity among nations, especially in sacred music culture, play an important role in different countries. If there is no support for cultural identity, any kind of music will be rejected by religion. The exchange and development between different nationalities can not exist. Therefore, cultural identity occupies an extremely important position in the Thai Thai cross-border musical and cultural exchanges.

\section{References}

[1] Minkang Yang. The music study of the buddhist festival of southern Buddhism of the dai nationality [M]. Beijing: religious culture press, 2003:89.

[2] Li Dong, Qingan Li, Congde Lin. Cultural identity in the field of psychology [J]. Journal of Beijing normal university (social science edition), 2014, (01):68-75.

[3] Lingjing Cao, Yiju Chen. A brief discussion on the similarities and differences between Chinese yunnan and the northern Thai people's music [J]. Popular art, 2016, (01):47-48.

[4] Minkang Yang. Research on the music culture of the transboundary ethnic group in southern China [M]. Beijing: central music college press, 2015:100.

[5] Weilin Li. The inheritance, dissemination and cultural identity of "Khaplue" in northern Thailand [J]. National art, 2016, (02):162-166.

[6] Bin Hu. Cultural identity -- an important theoretical perspective of music anthropology [J]. Music art (journal of music college Shanghai), 2010, (03):70-75+5.

[7] Jiancheng Liang. Study on the comparison of two strings of stringed instruments in dai tai nationality [D]. Yunnan Art College, 2015.

[8] Guizhong Li. Xishuangbanna dai religion music culture research [J]. National music, 2016, (06):26-29.

[9] Xu Chen. The research on the culture of music in yunnan dai nationality [J]. Guizhou ethnic studies, 2013, (05):61-64.

[10] Chen Dong. A study on the style of music recitations in the southern Chinese Buddhism spreading area of yunnan [D]. Yunnan Art College, 2013.

[11] Minkang Yang. The comparative study on the urbanization of music in China and the surrounding south of China and the Buddhism of Chinese Buddhism [J]. Music art (journal of Shanghai music college), 2013, (01):109-118+7. 